\title{
Desain Modifikasi Struktur Gedung Asrama Lembaga Penjamin Mutu Pendidikan (LPMP) Sumatera Barat Menggunakan SRPMK dan Balok Prategang pada Lantai Atap
}

\author{
Muhammad Satrya Ageta, Endah Wahyuni, dan Bambang Piscesa \\ Departemen Teknik Sipil, Fakultas Teknik Sipil, Lingkungan, dan Kebumian, \\ Institut Teknologi Sepuluh Nopember (ITS) \\ e-mail: endah@ce.its.ac.id
}

\begin{abstract}
Abstrak-Kompleks Lembaga Penjamin Mutu Pendidikan (LPMP) berlokasi di Kota Padang. Kebutuhan akan ruang dan kurangnya lahan pada komplek LPMP merupakan tantangan yang harus diatasi dalam pembangunan. Bangunan bertingkat banyak adalah salah satu solusi pembangunan terhadap kurangnya lahan dan ruang. Perencanaan gedung asrama LPMP setinggi 10 lantai $( \pm 40 \mathrm{~m})$ dirancang menggunakan beton bertulang pada keseluruhan lantai, serta menggunakan beton prategang pada balok lantai atap. Lantai atap tersebut akan didesain sebagai ruang ballroom tanpa ada struktur kolom ditengah ruangan. Sehingga, ruang ballroom menjadi lebih nyaman dan luas dibandingkan jika menggunakan balok nonprategang yang dapat menghasilkan dimensi lebih besar. Pada era modern ini beton prategang merupakan salah satu teknologi struktur yang dikembangkan dan sering digunakan untuk pembangunan gedung bertingkat yang memiliki balok dengan bentang yang cukup panjang tanpa ada kolom ditengah bentang. Balok beton prategang pada gedung bertingkat memiliki kendala dari sifat beton prategang yang getas. Oleh karena itu, diperlukan perencanaan khusus dalam desain balok beton prategang agar dapat bersifat daktail yang cukup untuk menahan beban gempa yaitu berupa metode pelaksanaan pekerjaan balok beton prategang dengan metode penarikan posttension dan cast in situ, sehingga hubungan balok prategang dan kolom monolit. Struktur gedung LPMP menggunakan Sistem Rangka Pemikul Momen Khusus (SRPMK). Dimana sistem ini dirancang untuk daerah rawan gempa sesuai peraturan SNI 1726:2012, untuk pembebanan sesuai peraturan SNI 2847:2013, dan analisa struktur menggunakan program bantu SAP2000.
\end{abstract}

Kata Kunci-Balok Beton Prategang, Sistem Rangka Pemikul Momen Khusus, Asrama LPMP Padang.

\section{PENDAHULUAN}

$\mathrm{K}$ OMPLEKS Lembaga Penjamin Mutu Pendidikan (LPMP) berlokasi di Kota Padang. Kebutuhan akan ruang dan kurangnya lahan pada komplek LPMP merupakan tantangan yang harus diatasi dalam pembangunan. Bangunan bertingkat banyak adalah salah satu solusi pembangunan terhadap kurangnya lahan dan ruang [1].

Gedung asrama LPMP merupakan gedung yang difungsikan sebagai hunian dan juga ruang kelas. Struktur gedung asrama LPMP merupakan struktur beton bertulang biasa. Pada jurnal ini akan dilakukan modifikasi pada balok lantai atap, dimana dibawah lantai atap yaitu pada lantai 10 akan digunakan sebagai ballroom. Ballroom tidak menggunakan kolom ditengah ruangan, sehingga digunakan balok prategang. Penggunaan balok prategang lebih efektif digunakan dibandingkan dengan balok bertulang biasa. Hal ini dikarenakan bentang balok yang panjang, yaitu 20 meter, apabila menggunakan beton bertulang biasa akan menghasilkan dimensi yang besar dan tulangan yang banyak.

Beton prategang merupakan teknologi konstruksi beton yang mengkombinasikan dua jenis bahan mutu tinggi, yaitu beton (High Strength Concrete) dan baja (High Strength Steel), dengan cara menarik baja tersebut dan menahannya ke beton, sehingga membuat beton dalam keadaan tertekan [2].

Komponen struktur beton prategang memiliki dimensi tinggi balok lebih kecil dibandingkan dengan beton bertulang untuk kondisi beban dan bahan yang sama. Pada umumnya tinggi komponen struktur beton prategang berkisar antara 65 sampai 80 persen dari tinggi komponen struktur beton bertulang [3].

Struktur bangunan gedung asrama LPMP dirancang menggunakan system rangka pemikul momen khusus, karena gedung asrama LPMP berada diwilayah zona gempa tinggi. Perencanaan struktur dilakukan dengan menggunakan panduan tata cara perhitungan beton untuk bangunan gedung yaitu SNI 2847:2013, perencanaan ketahanan gempa untuk bangunan gedung SNI 1726:2012, dan peraturan pembebanan PPIUG 1987 yang diharapkan dapat menghasilkan suatu struktur gedung yang memenuhi segala persyaratan keamanan struktur.

\section{URAIAN PENELITIAN}

Beton prategang merupakan teknologi konstruksi beton yang mengkombinasikan antara beton berkekuatan tinggi dengan baja mutu tinggi dengan cara aktif. Beton prategang merupakan kombinasi yang ideal dari dua buah bahan modern yang berkekuatan tinggi [2].

Terdapat dua jenis metode pada beton prategang, diantaranya metode pra-tarik (Pre Tension) dan metode pascatarik (Post Tension). Istilah pra-tarik digunakan untuk menggambarkan metode prategang dimana setelah penarikan tendon baja dilakukan, kemudian beton dicor. Kebalikan dari metode pra-tarik, metode pasca-tarik adalah metode prategang dimana tendon baja ditarik setelah beton mengeras. Pada tugas 
akihr ini, metode beton prategang yang digunakan ialah metode beton prategang pasca-tarik (Post Tension), dikarenakan metode ini memungkinkan pembuatan tendon berbentuk parabola (menyesuaikan dengan bentuk bidang momen), sehingga penampang beton disepanjang bentang dapat menerima tegangan lebih efisien dibandingkan dengan menggunakan tendon lurus [2][3].

Sistem struktur bangunan gedung yang sering dilaksanakan pada pembangunan gedung di Indonesia pada umumnya menggunakan sistem struktur ganda dan sistem struktur rangka pemikul momen. Sistem struktur ganda diantaranya merupakan kombinasi sistem struktur rangka pemikul momen dan dinding struktural atau dinding geser. Pada sistem struktur rangka pemikul momen terdapat tiga jenis yaitu Sistem Rangka Pemikul Momen Biasa (SRPMB), Sistem Rangka Pemikul Momen Menengah (SRPMM), dan Sistem Rangka Pemikul Momen Khusus (SRPMK). Pada perencanaan ini menggunakan SRPMK [4].

Sistem Rangka Pemikul Momen Khusus (SRPMK) yaitu komponen struktur yang mampu memikul gaya akibat beban gempa dan direncanakan untuk memikul aksi lentur, geser, dan aksial. Sistem ini pada dasarnya memiliki daktilitas penuh dan wajib digunakan di zona resiko gempa tinggi yaitu zona 5 dan $6[4]$.

\section{METODOLOGI}

\section{A. Uтит}

Jurnal ini membahas perencanaan struktur balok prategang yang terdapat pada lantai atap dengan menggunakan metode post tension, yaitu pemberian gaya prategang dilakukan setelah balok selesai dicor dan cukup keras dan kuat menahan tegangan. Langkah-langkah pengerjaan jurnal dijelaskan dalam diagram alir pada Gambar 1.

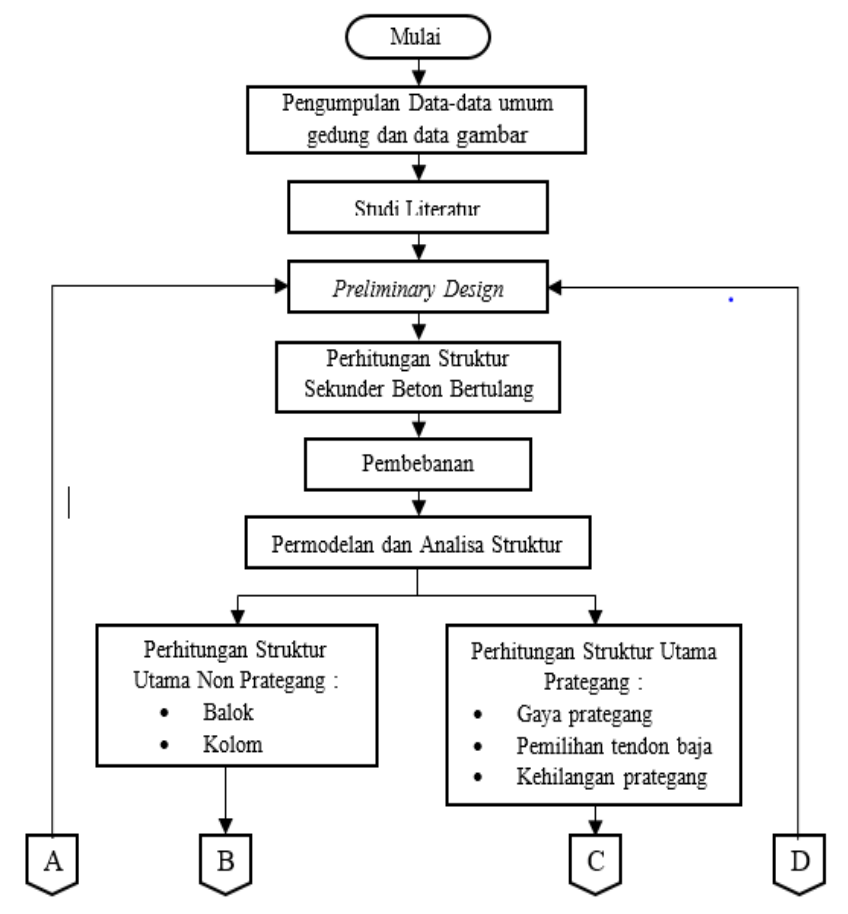

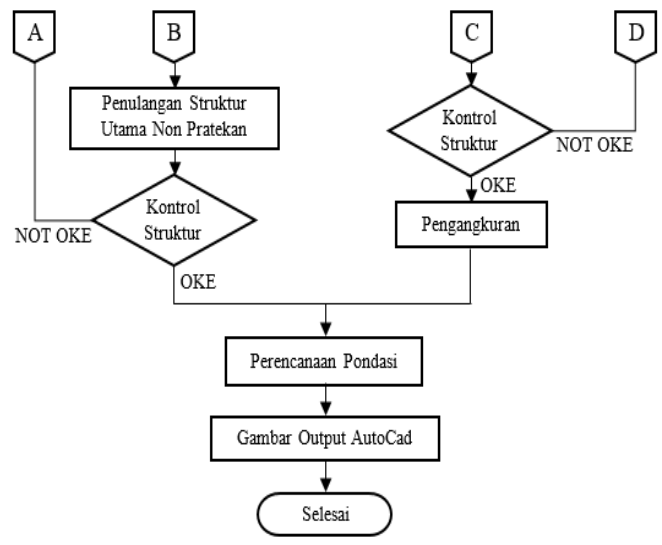

Gambar 1. Metode penelitian jurnal.

\section{B. Data-data Perencanaan Struktur}

Data-data pada perencanaan struktur gedung ini merupakan data-data yang akan dijadikan pedoman dalam perencanaan selanjutnya. Data-data yang digunakan adalah sebagai berikut :
a. Fungsi bangunan : Asrama dan apartemen
b. Tipe bangunan : Gedung bertingkat
c. Tinggi bangunan $: \pm 40 \mathrm{~m}$
d. Luas bangunan $\quad: 33 \mathrm{~m} \mathrm{x} 26 \mathrm{~m}=858 \mathrm{~m}^{2}$
e. Mutu beton $\left(\mathrm{f}^{\prime} \mathrm{c}\right)$ kolom : $35 \mathrm{MPa}$ (lantai 1-5)
: $30 \mathrm{MPa}$ (lantai 6-10)
f. Mutu beton $\left(\mathrm{f}^{\prime}{ }_{\mathrm{c}}\right)$ balok $: 35 \mathrm{MPa}$
: $40 \mathrm{MPa}$ (balok prategang)
g. Mutu beton $\left(\mathrm{f}^{\prime}{ }_{\mathrm{c}}\right)$ pelat $: 35 \mathrm{MPa}$
h. Mutu baja $\left(\mathrm{f}_{\mathrm{y}}\right) \quad: 420 \mathrm{MPa}$

C. Kombinasi Pembebanan

Kombinasi pembebanan yang diterapkan pada bangunan ini sebagai berikut [5]:

1. $1.4 \mathrm{D}$

2. $1.2 \mathrm{D}+1.6 \mathrm{~L}+0.5 \mathrm{R}$

3. $1.2 \mathrm{D}+1.6 \mathrm{R}+0.5 \mathrm{~L}$

4. $1.2 \mathrm{D}+1.0 \mathrm{~W} 1.0 \mathrm{~L}+0.5 \mathrm{R}$

5. $1.2 \mathrm{D}+1.0 \mathrm{E}+1.0 \mathrm{~L}$

6. $0.9 \mathrm{D}+1.0 \mathrm{~W}$

7. $0.9 \mathrm{D}+1.0 \mathrm{E}$

\section{Permodelan dan Analisis Struktur}

Analisa struktur dilakukan dengan program bantu SAP. Permodelan struktur ini dapat dilihat pada Gambar 2.

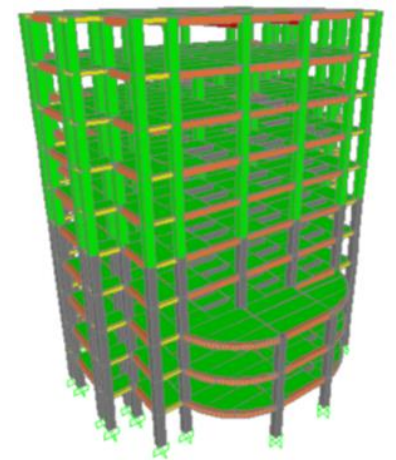

Gambar 2 Permodelan Modifikasi Struktur Gedung. 
Struktur sekunder yang dihitung adalah pelat, tangga, balok anak,dan balok lift, sedangkan struktur utama yang dihitung adalah balok induk, kolom, dan balok pratekan. Dan untuk struktur bawah yang dihitung adalah sloof, tiang pancang dan pilecap.

\section{E. Kontrol Perioda}

Nilai T (waktu getar alami struktur) dibatasi oleh waktu getar alami fundamental untuk mencegah pengunaan struktur yang terlalu fleksibel. Periode fundamental, T, tidak boleh melebihi hasil koefisien untuk batasan atas pada periode yang dihitung $\left(\mathrm{C}_{\mathrm{u}}\right)$ dan periode fundamental pendekatan, $\mathrm{T}_{\mathrm{a}}[5][6]$, dan [7].

Kontrol perioda yang terjadi dapat dilihat pada Tabel 1 .

Tabel 1

Kontrol Perioda

\begin{tabular}{ccc}
\hline \hline Case & Mode & Periode \\
\hline Modal & 1 & 1.439 \\
Modal & 2 & 1.270 \\
Modal & 3 & 1.181 \\
Modal & 4 & 0.488 \\
Modal & 5 & 0.421 \\
Modal & 6 & 0.382 \\
Modal & 7 & 0.271 \\
Modal & 8 & 0.238 \\
Modal & 9 & 0.159 \\
Modal & 10 & 0.147 \\
Modal & 11 & 0.099 \\
Modal & 12 & 0.075 \\
\hline \hline
\end{tabular}

Perbandingan nilai untuk periode fundamental struktur sebagai berikut :

$\mathrm{T}_{\mathrm{a}} \leq \mathrm{T} \leq \mathrm{C}_{\mathrm{u}} \cdot \mathrm{T}_{\mathrm{a}}$

$1.289 \mathrm{~s} \leq 1.439 \mathrm{~s} \leq 1.805 \mathrm{~s} \quad(\mathrm{OK})$

Maka berdasarkan kontrol waktu fundamental, nilai $\mathrm{T}$ masih lebih kecil dari $\mathrm{C}_{\mathrm{u}} \cdot \mathrm{T}_{\mathrm{a}}$, jadi analisis struktur memenuhi syarat.

\section{F. Kontrol Gaya Geser Dasar (Base Shear)}

Kontrol gaya dinamis struktur digunakan untuk melihat apakah gaya gempa yang dimasukkan dengan menggunakan respon spectrum sudah sesuai dengan yang disyaratkan SNI 1726:2012 pasal 7.8.1 [5][8], dan [9]. Hasil kontrol geser dasar dapat dilihat pada Tabel 2.

Tabel 2.

Kontrol Akhir Berdasarkan Faktor Skala Gaya Gempa

\begin{tabular}{ccc}
\hline \hline \multirow{2}{*}{ Load Case/Combo } & $\mathrm{FX}$ & $\mathrm{FY}$ \\
\cline { 2 - 3 } & $\mathrm{kN}$ & $\mathrm{kN}$ \\
\hline Gempa x max & 4722.299 & 297.382 \\
Gempa y max & 308.916 & 4722.299 \\
\hline \hline
\end{tabular}

$\mathrm{V}_{\text {statik }}=5555.650 \mathrm{kN}$

Untuk Arah x :

$\mathrm{V}_{\mathrm{tx}} \quad>0.85 \mathrm{~V}_{\text {statik }}$

$4722.299 \mathrm{kN}>0.85 \times 5555.650 \mathrm{kN}$

$4722.299 \mathrm{kN}>4722.298 \mathrm{kN}$

(Ok)

Untuk Arah y :

$\mathrm{V}_{\mathrm{ty}}>0.85 \mathrm{~V}$

$4722.299 \mathrm{kN}>0.85 \times 5555.650 \mathrm{kN}$

$4722.299 \mathrm{kN}>4722.298 \mathrm{kN}$

(Ok)

\section{G. Kontrol Partisipasi Massa}

Sesuai SNI 1726:2012 Ps 7.9.1 perhitungan respons dinamik struktur harus sedemikian rupa sehingga partisipasi massa dalam menghasilkan respon total sekurang kurangnya adalah 90\% [5][10]. Hasil kontrol partisipasi massa dapat dilihat pada tabel 3 .

Tabel 3

Rasio Partisipasi Massa

\begin{tabular}{ccccc}
\hline \hline Case & Mode & Perioda & Sum UX & Sum UY \\
\hline Modal & 1 & 1.439 & 0.731 & 0.000 \\
Modal & 2 & 1.270 & 0.731 & 0.766 \\
Modal & 3 & 1.181 & 0.745 & 0.766 \\
Modal & 4 & 0.487 & 0.871 & 0.766 \\
Modal & 5 & 0.420 & 0.871 & 0.887 \\
Modal & 6 & 0.383 & 0.872 & 0.887 \\
Modal & 7 & 0.271 & 0.929 & 0.887 \\
Modal & 8 & 0.238 & 0.929 & 0.932 \\
Modal & 9 & 0.159 & 0.938 & 0.947 \\
Modal & 10 & 0.147 & 0.964 & 0.959 \\
Modal & 11 & 0.099 & 0.983 & 0.975 \\
Modal & 12 & 0.075 & 0.992 & 0.997 \\
\hline \hline
\end{tabular}

Dari hasil perencanaan didapatkan partisipasi massa dalam menghasilkan respon total minimal $90 \%$ didapatkan mulai dari mode 8 .

\section{H. Kontrol Simpangan Antar Lantai (Drift)}

Gempa menyebabkan struktur bertingkat rawan terhadap terjadinya simpangan horizontal (drift). Apabila simpangan horizontal ini melebihi syarat aman yang telah ditentukan maka gedung akan mengalami keruntuhan.

Sesuai SNI 1726:2012 Pasal 7.8.6 [5][11] kontrol drift dan syarat drift harus ditentukan sebagai berikut :

$\delta_{x}=\frac{C_{d} \cdot \delta_{e x}}{I_{e}}$

Hasil kontrol simpangan dapat dilihat pada Tabel 4 dan 5 .

Tabel 4

Kontrol Simpangan Antar Lantai Portal Gempa Dinamis Arah X

\begin{tabular}{cccccccc}
\hline \hline \multirow{2}{*}{$\mathrm{Lt}$} & $\mathrm{hi}$ & $\mathrm{hsx}$ & $\delta \mathrm{ei}$ & $\delta \mathrm{i}$ & $\Delta \mathrm{i}$ & $\Delta \mathrm{o}$ & Ket \\
\cline { 2 - 7 } & $(\mathrm{m})$ & $(\mathrm{m})$ & $(\mathrm{mm})$ & $(\mathrm{mm})$ & $(\mathrm{mm})$ & $(\mathrm{mm})$ & $(\mathrm{mm})$ \\
\hline Atap & 40 & 4 & 63.745 & 350.599 & 17.883 & 80 & OK \\
10 & 36 & 4 & 60.494 & 332.717 & 25.600 & 80 & OK \\
9 & 32 & 4 & 55.839 & 307.117 & 30.999 & 80 & OK \\
8 & 28 & 4 & 50.203 & 276.118 & 35.799 & 80 & OK \\
7 & 24 & 4 & 43.694 & 240.319 & 41.129 & 80 & OK \\
6 & 20 & 4 & 36.216 & 199.190 & 44.930 & 80 & OK \\
5 & 16 & 4 & 28.047 & 154.261 & 46.117 & 80 & OK \\
4 & 12 & 4 & 19.662 & 108.143 & 45.285 & 80 & OK \\
3 & 8 & 4 & 11.429 & 62.859 & 41.043 & 80 & OK \\
2 & 4 & 4 & 3.966 & 21.815 & 21.815 & 80 & OK \\
1 & 0 & 4 & 0.000 & 0.000 & 0.000 & 80 & OK \\
\hline \hline
\end{tabular}

Kontrol Simpangan Antar Lantai Portal Gempa Dinamis Arah Y

\begin{tabular}{cccccccc}
\hline \hline \multirow{2}{*}{ Lt } & hi & hsx & $\delta$ ei & $\delta \mathrm{i}$ & $\Delta \mathrm{i}$ & $\Delta \mathrm{o}$ & Ket \\
\cline { 2 - 7 } & $(\mathrm{m})$ & $(\mathrm{m})$ & $(\mathrm{mm})$ & $(\mathrm{mm})$ & $(\mathrm{mm})$ & $(\mathrm{mm})$ & $(\mathrm{mm})$ \\
\hline Atap & 40 & 4 & 44.982 & 247.404 & 10.895 & 80 & OK \\
10 & 36 & 4 & 43.002 & 236.509 & 15.101 & 80 & OK \\
9 & 32 & 4 & 40.256 & 221.407 & 20.343 & 80 & OK \\
8 & 28 & 4 & 36.557 & 201.064 & 25.262 & 80 & OK \\
7 & 24 & 4 & 31.964 & 175.802 & 29.462 & 80 & OK \\
6 & 20 & 4 & 26.607 & 146.340 & 32.282 & 80 & OK \\
5 & 16 & 4 & 20.738 & 114.058 & 33.531 & 80 & OK \\
4 & 12 & 4 & 14.641 & 80.527 & 32.769 & 80 & OK \\
3 & 8 & 4 & 8.683 & 47.758 & 30.571 & 80 & OK \\
2 & 4 & 4 & 3.125 & 17.187 & 17.187 & 80 & OK \\
1 & 0 & 4 & 0.000 & 0.000 & 0.000 & 80 & OK \\
\hline \hline
\end{tabular}


Dari hasil perencanaan didapatkan simpangan yang terjadi tidak melebihi syarat aman. Jadi dapat disimpulkan gedung aman dari keruntuhan.

\section{HASIL DAN PEMBAHASAN}

\section{A. Preliminary Design}

Preliminary design merupakan tahapan dalam perencanaan dimensi awal dari suatu elemen struktur.

1. Balok

Dimensi balok yang disyaratkan [12] tertera pada tabel 6 dan tabel 7 adalah sebagai berikut :

Tabel 6

Rekapitulasi Balok Induk

\begin{tabular}{|c|c|c|c|c|}
\hline \multirow{2}{*}{ No } & \multirow{2}{*}{ Tipe balok } & \multicolumn{3}{|c|}{ Tinggi (h) } \\
\hline & & $(\mathrm{cm})$ & $(\mathrm{cm})$ & $(\mathrm{cm})$ \\
\hline 1 & BI-1 & 700 & 60 & 40 \\
\hline 2 & BI-2 & 300 & 40 & 30 \\
\hline 3 & BI-3 & 500 & 60 & 40 \\
\hline 4 & BI-4 & 200 & 40 & 30 \\
\hline 5 & BI-5 & 600 & 60 & 40 \\
\hline \multicolumn{5}{|c|}{ Tabel 7} \\
\hline \multirow{2}{*}{ No } & \multirow{2}{*}{ Tipe balok } & Bentang & Tinggi (h) & Lebar (b) \\
\hline & & $(\mathrm{cm})$ & $(\mathrm{cm})$ & $(\mathrm{cm})$ \\
\hline 1 & BA-1 & 700 & 45 & 30 \\
\hline 2 & BA-2 & 240 & 20 & 20 \\
\hline
\end{tabular}

\section{Kolom}

Dimensi kolom yang disyaratkan [12] adalah sebagai berikut: Dimensi kolom $80 \mathrm{~cm}$ x $80 \mathrm{~cm}$.

3. Pelat

Dimensi pelat yang disyaratkan [12] adalah sebagai berikut :

Pelat Lantai Hunian $\quad=12 \mathrm{~cm}$

Pelat Atap $\quad=12 \mathrm{~cm}$

4. Tangga

Tangga adalah sebuah konstruksi yang dirancang untuk menghubungi dua tingkat vertikal yang memiliki jarak satu sama lain.

Data teknis perencanaan tangga :

Lebar injakan (i) $\quad: 30 \mathrm{~cm}$

Tinggi injakan $(\mathrm{t}) \quad: 17 \mathrm{~cm}$

Tinggi tangga $\quad: 400 \mathrm{~cm}$

Tinggi bordes $\quad: 200 \mathrm{~cm}$

Panjang datar tangga $: 330 \mathrm{~cm}$

Panjang miring tangga : $386 \mathrm{~cm}$

Sudut kemiringan ;

$$
\begin{aligned}
& \alpha=\arctan \frac{t}{i} \\
& \alpha=29.64^{\circ}
\end{aligned}
$$

Syarat sudut kemiringan :

$$
\begin{aligned}
& 25^{\circ} \leq \alpha \leq 40^{\circ} \\
& 25^{\circ} \leq 29.54^{\circ} \leq 40^{\circ} \text { (memenuhi) }
\end{aligned}
$$

\section{B. Perencanaan Struktur Sekunder}

\section{Pelat}

Hasil perhittungan penulangan pelat tertera pada Tabel 8 .

$\mathrm{f}^{\prime}{ }_{\mathrm{c}}=35 \mathrm{MPa}$

$\mathrm{f}_{\mathrm{y}}=420 \mathrm{Mpa}$
Tabel 8

Rekapitulasi Penulangan Pelat

\begin{tabular}{ccccccc}
\hline \hline & & \multicolumn{2}{c}{ Tumpuan } & \multicolumn{2}{c}{ Lapangan } & \\
\cline { 3 - 6 } Tipe & Lantai & Tul. & Tul. & Tul. & Tul. & \\
& & Utama & Pembagi & Utama & Pembagi & \\
\hline \multirow{2}{*}{ A } & $1-9$ & $\varnothing 10-100$ & $\varnothing 10-200$ & $\varnothing 10-100$ & $\varnothing 10-200$ & Satu \\
& 10 & $\varnothing 10-100$ & $\varnothing 10-200$ & $\varnothing 10-100$ & $\varnothing 10-200$ & Arah \\
& Atap & $\varnothing 10-100$ & $\varnothing 10-200$ & $\varnothing 10-100$ & $\varnothing 10-200$ & \\
Tipe & Lantai & \multicolumn{2}{c}{ Tumpuan } & Lapangan & \\
& $1-9$ & $\varnothing 10-100$ & $\varnothing 10-100$ & $\varnothing 10-100$ & $\varnothing 10-100$ & \\
B & 10 & $\varnothing 10-100$ & $\varnothing 10-100$ & $\varnothing 10-100$ & $\varnothing 10-100$ & \\
& Atap & $\varnothing 10-100$ & $\varnothing 10-100$ & $\varnothing 10-100$ & $\varnothing 10-100$ & Dua \\
& $1-9$ & $\varnothing 10-100$ & $\varnothing 10-100$ & $\varnothing 10-100$ & $\varnothing 10-100$ & Arah \\
C & 10 & $\varnothing 10-100$ & $\varnothing 10-100$ & $\varnothing 10-100$ & $\varnothing 10-100$ & \\
& Atap & $\varnothing 10-100$ & $\varnothing 10-100$ & $\varnothing 10-100$ & $\varnothing 10-100$ & \\
D & $1-9$ & $\varnothing 10-100$ & $\varnothing 10-100$ & $\varnothing 10-100$ & $\varnothing 10-100$ & \\
\hline \hline
\end{tabular}

2. Tangga

Hasil perhittungan penulangan tangga dan bordes tertera pada tabel 9.

$$
\begin{array}{ll}
\mathrm{f}_{\mathrm{c}}=35 & \mathrm{MPa} \\
\mathrm{f}_{\mathrm{y}}=420 & \mathrm{Mpa}
\end{array}
$$

Tabel 9

Rekapitulasi Penulangan Pelat Tangga

\begin{tabular}{ccc}
\hline \hline \multirow{2}{*}{ Nama struktur } & \multicolumn{2}{c}{ Tulangan } \\
\cline { 2 - 3 } & Lentur & Bagi \\
\hline Pelat tangga & D16-140 & $\varnothing 10-300$ \\
Pelat bordes & D16-200 & $\varnothing 10-300$ \\
Nama struktur & Lentur & Geser \\
Balok bordes & 3D16 & $\varnothing 10-150$ \\
\hline \hline
\end{tabular}

\section{Balok Anak}

Hasil perhittungan penulangan balok anak tertera pada tabel 10 dan 11.

$$
\begin{array}{ll}
\mathrm{f}^{\prime}{ }_{\mathrm{c}}=35 & \mathrm{MPa} \\
\mathrm{f}_{\mathrm{y}}=420 & \mathrm{Mpa} \\
\mathrm{f}_{\mathrm{yv}}=240 & \mathrm{Mpa}
\end{array}
$$

Tabel 10

Rekapitulasi Penulangan Memanjang Balok Anak (BA)

\begin{tabular}{ccccccc}
\hline \hline \multirow{2}{*}{ Tipe } & \multicolumn{2}{c}{ Tumpuan Kiri } & \multicolumn{2}{c}{ Lapangan } & \multicolumn{2}{c}{ Tumpuan Kanan } \\
\cline { 2 - 7 } & Positif & Negatif & Negatif & Positif & Positif & Negatif \\
\hline BA 1 Tepi & 3D16 & 2D16 & 2D16 & 4D16 & 4D16 & 2D16 \\
BA 1 Tengah & 4D16 & 2D16 & 2D16 & 3D16 & 4D16 & 2D16 \\
BA 1 Tepi & 2D13 & 2D13 & 2D13 & 2D13 & 2D13 & 2D13 \\
BA 1 Tengah & 2D13 & 2D13 & 2D13 & 2D13 & 2D13 & 2D13 \\
\hline \hline
\end{tabular}

Tabel 11

Rekapitulasi Penulangan Geser Balok Anak

\begin{tabular}{ccc}
\hline \hline \multirow{2}{*}{ Tipe } & \multicolumn{2}{c}{ Tulangan Geser } \\
\cline { 2 - 3 } & Tunpuaan & Lapangan \\
\hline BA 1 Tepi & $\varnothing 100-150$ & $\varnothing 100-150$ \\
BA 1 Tengah & $\varnothing 100-150$ & $\varnothing 100-150$ \\
BA 1 Tepi & $\varnothing 100-150$ & $\varnothing 100-150$ \\
BA 1 Tengah & $\varnothing 100-150$ & $\varnothing 100-150$ \\
\hline \hline
\end{tabular}

\section{Perencanaan Struktur Primer}

1. Balok Induk (BI)

Hasil perhittungan penulangan balok induk tertera pada

Tabel 12. 
Tabel 12

Rekapitulasi Balok Induk (BI)

\begin{tabular}{cccccccc}
\hline \hline \multirow{2}{*}{ Tipe } & \multirow{2}{*}{ Torsi } & \multicolumn{2}{c}{ Tumpuan } & \multicolumn{2}{c}{ Lapangan } & \multicolumn{2}{c}{ Tulangan Geser } \\
\cline { 3 - 7 } & & - & + & - & + & Tum & Lap \\
\hline BI 1 & 2D16 & 6D22 & 4D22 & 4D22 & 5D22 & D13-150 & D13-250 \\
BI 2 & 1D16 & 5D22 & 5D22 & 2D22 & 3D22 & D13-100 & D13-150 \\
\hline \hline
\end{tabular}

2. Kolom

Hasil perhittungan penulangan kolom tertera pada tabel 13 .

Tabel 13

Rekapitulasi Kolom

\begin{tabular}{cccccc}
\hline \hline \multirow{2}{*}{ Tipe } & $\begin{array}{c}\text { Penulangan } \\
\text { Lentur }\end{array}$ & \multicolumn{2}{c}{ Tulangan Geser } & lo & $\begin{array}{c}\text { Sambungan } \\
\text { Lewatan }\end{array}$ \\
\cline { 3 - 6 } & & Tumpuan & Lapangan & $(\mathrm{mm})$ & \\
\hline K 1t 1-5 & 20D22 & 4D13-90 & 4D13-130 & 800 & 600 \\
K 1t 6-10 & 20D22 & 4D13-110 & 4D13-130 & 800 & 700 \\
\hline \hline
\end{tabular}

\section{Perencanaan Balok Prategang}

Metode konsep desain untuk mendesain elemen beton prategang, tegangan serat beton dihitung dari gaya luar yang bekerja dibeton akibat pemberian prategang awal dan beban luar transversal. Balok prategang direncanakan dengan metode penarikan post tension, digunakan pada balok lantai atap diruang ballroom. Penampang balok prategang dapat dilihat pada gambar 3.

Dimensi balok : 700/1000

$$
\begin{array}{ll}
\text { Bentang } & : 20000 \mathrm{~mm} \\
\mathrm{f}^{\prime}{ }_{\mathrm{c}} & : 40 \mathrm{MPa}
\end{array}
$$

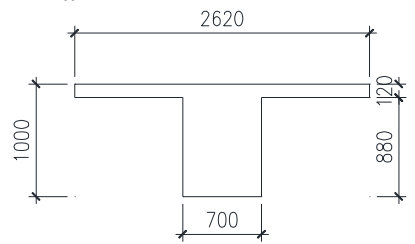

Gambar 3. Penampang Balok Prategang.

Tegangan awal $: 3500 \mathrm{kN}$

Tipe strand : ASTM A 416-96 grade 270

Diameter $: 15.24 \mathrm{~mm}$

Luas penampang : $140 \mathrm{~mm}^{2}$

Jumlah strand $\quad: 22$ buah

Jumlah tendon $: 1$ buah

Tabel 14

Kehilangan Prategang

\begin{tabular}{lcc}
\hline \hline \multirow{2}{*}{ Macam Kehilangan Prategang } & $\begin{array}{c}\text { Kehilangan } \\
\text { Gaya Prategang }\end{array}$ & Persentase \\
\cline { 2 - 3 } & Mpa & $\%$ \\
\hline Tegangan Efektif & 1303.5 & $100 \%$ \\
$\quad$ Sesudah penarikan 0.7 fpu & & \\
Kehilangan Langsung & 0 & $0.00 \%$ \\
1. kehilangan perpendekan elastis & 49.834 & $3.82 \%$ \\
2. kehilangan angker slip & 77.607 & $5.95 \%$ \\
3. kehilangan wobble effect & 0.31 & $2.88 \%$ \\
4. kehilangan kekangan kolom & & \\
Kehilangan tak langsung & 80.192 & $6.15 \%$ \\
1. kehilangan rangkak & 48.665 & $3.73 \%$ \\
2. kehilangan susut & 68.829 & $5.28 \%$ \\
3. kehilangan relaksasi baja & 328.875 & $25.23 \%$ \\
Total kehilangan & 974.625 & $74.77 \%$ \\
Tegangan Efektif & & \\
\hline \hline
\end{tabular}

Penulangan Lunak tambahan :

Tulangan puntir : 4D16

Tulangan lentur

- Tumpuan negative : 9D25

- Tumpuan positif : 5D25

- Lapangan bawah : 8D25

- Lapangan atas : 4D25

- Geser tumpuan : :2D13-200 mm

- Geser lapangan : : 2D13-300 mm
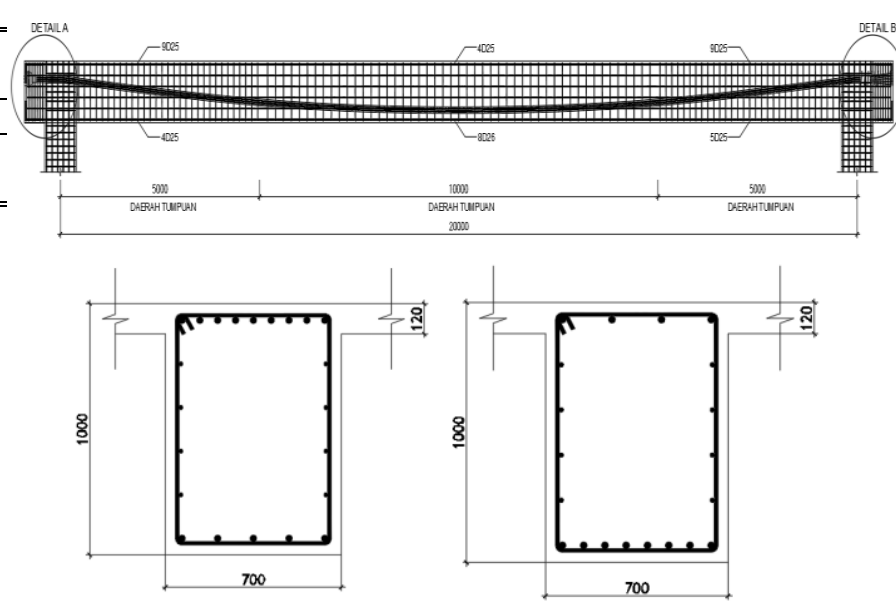

Gambar 4. Desain Penulangan Balok Prategang

\section{E. Perencanaan Pondasi}

Tipe pondasi : tiang pancang

Tipe tiang pancang : kelas A

Diameter luar $\quad: 600 \mathrm{~mm}$

Tebal dinding $\quad: 100 \mathrm{~mm}$

Allowable axial load : 252.7 ton

Berat tiang pancang : $393 \mathrm{~kg} / \mathrm{m}$

Pajang tiang : : 6-16 meter

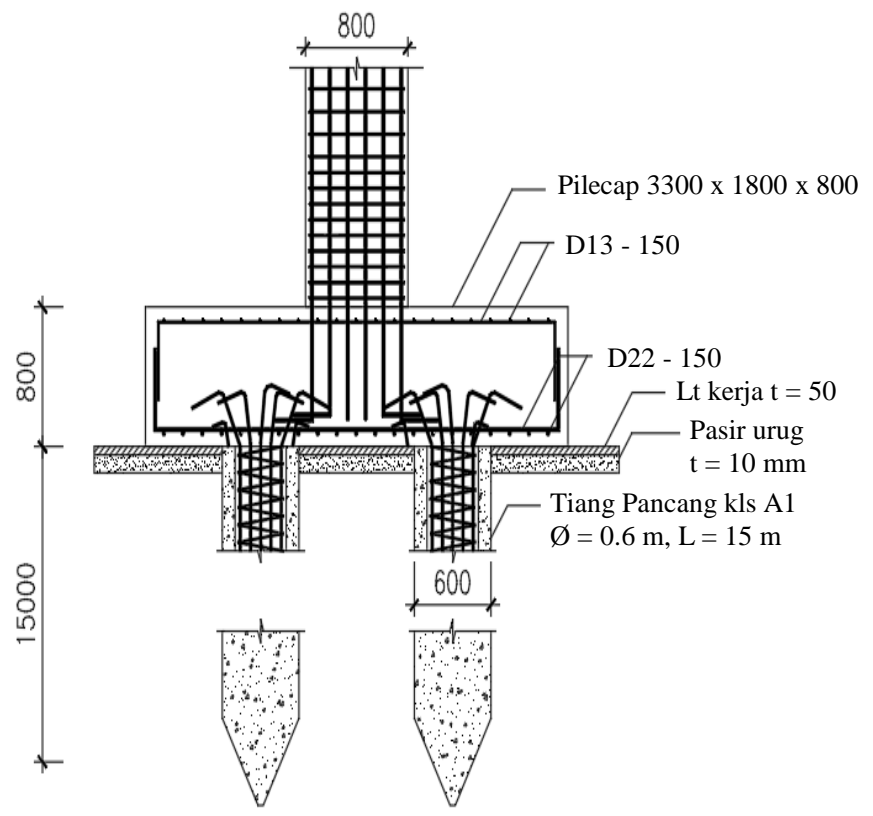

Gambar 5. Penulangan Pilecap. 


\section{KESIMPULAN}

Dari perhitungan-perhitungan yang telah dijelaskan pada bab sebelumnya didapatkan kesimpulan sesuai tujuan penulisan Jurnal "Desain modifikasi struktur gedung asrama LPMP sumatera barat menggunakan SRPMK dan balok prategang pada lantai atap" dengan gambar teknis pada lampiran dan hasil analisa sebagai berikut :

1. Dari hasil perhitungan preliminary desain, didapatkan data data perencanaan dimensi yang meliputi struktur sekunder, struktur primer non pratekan dan struktur primer pratekan sebagai berikut :

- Struktur sekunder:

- Balok anak tipe $1=30 / 45$

- Balok anak tipe $2=20 / 20$

- Balok lift $\quad=30 / 40$

- Balok bordes $\quad=20 / 20$

- Tebal pelat $($ semua tipe pelat $)=12 \mathrm{~cm}$

- Tebal pelat tangga $\quad=15 \mathrm{~cm}$

- Tebal pelat bordes $\quad=15 \mathrm{~cm}$

- Struktur primer:

- Balok induk tipe 1,3,5=40/60

- Balok induk tipe 2,3 = 30/40

- Balok pratekan $\quad=70 / 100$

- Kolom tipe $1=80 / 80$

- Kolom tipe $2=80 / 80$

2. Dimensi balok prategang didapatkan $b=0.7 \mathrm{~m}$ dan $\mathrm{h}=1$ $\mathrm{m}$, dengan bentang $20 \mathrm{~m}$.

3. Balok prategang direncanakan dengan system pasca-tarik, didapatkan gaya prategang awal $3500 \mathrm{kN}$, dan didapatkan nilai kehilangan prategang sebesar $25.25 \%$.

4. Berdasarkan analisis perhitungan didapatkan jumlah strand 22 buah dengan menggunakan 1 buah tendon.

\section{DAFTAR PUSTAKA}

[1] B. O. Majore and Steenie, "Studi Perbandingan Respons Dinamik Bangunan Bertingkat Banyak Dengan Variasi Tata Letak Dinding Geser," J. Tek. Sipil Statik, vol. 3, no. 6, 2015.

[2] T. Y. Lin and N. H. Burn, Desain Struktur Beton Prategang Edisi Ketiga Jilid 1, Terjemahan. Jakarta: Binarupa Aksara, 2000.

[3] E. G. Nawy, Beton Prategang: Suatu Pendekatan Mendasar, 3rd ed. Jakarta: Erlangga, 2001.

[4] Tavio and B. Kusuma, Desain Sistem Rangka Pemikul Momen dan Dinding Struktur Beton Bertulang Tahan Gempa. Surabaya: ITS Press, 2009.

[5] Badan Standarisasi Nasional, "Tata Cara Perencanaan Ketahanan Gempa Untuk Bangunan Gedung (SNI 03-1726-2012)," Bandung, 2012.

[6] M. Z. Fauzi, E. Wahyuni, and B. Suswanto, "Modifikasi Perencanaan Struktur Gedung Apartemen Brooklyn Alam Sutera Menggunakan Struktur Komposit Baja-Beton dengan Sistem Rangka Berpengaku Eksentris," J. Tek. ITS, vol. 7, no. 1, pp. D6D11, 2018.

[7] L. Fitriyah, P. Suprobo, and E. Wahyuni, "Modifikasi Desain Struktur Gedung Hotel Holiday Inn Express Surabaya dengan Menggunakan Sistem Rangka Bresing Eksentrik," J. Tek. ITS, vol. 6, no. 2, pp. 271-D276, 2017.

[8] J. Pambudi, E. Wahyuni, and A. Sidharta, "Perencanaan Bangunan Kiln Menggunakan Metode Pracetak," J. Tek. ITS, vol. 6, no. 2, pp. D251-D256, 2017.

[9] Y. Yuliana, D. Iranata, and E. Wahyuni, "Modifikasi Perencanaan Struktur Gedung Tower C Apartemen Aspen Admiralty Jakarta Selatan dengan Menggunakan Baja-Beton Komposit," J. Tek. ITS, vol. 6, no. 2, pp. C588-C593, 2017.

[10] I. Budiono, E. Wahyuni, and Isdarmanu., "Perbandingan Berat Material Baja pada Perencanaan Struktur Baja Sistem Rangka Pengaku Eksentris (SRPE) dengan Sistem Staggered Trus Frames (STF) pada Apartemen Purimas Surabaya," J. Tek. ITS, vol. 6, no. 2, pp. D217-D223, 2017.

[11] A. Zaky, E. Wahyuni, and Isdarmanu., "Modifikasi Perencanaan Apartemen Grand Kamala Lagoon Menggunakan Struktur Baja Komposiit dengan Sistem Rangka Berpengaku Eksentris," J. Tek. ITS, vol. 6, no. 2, pp. D198-D204, 2017.

[12] Badan Standarisasi Nasional, "SNI 2847:2013 Tata Cara Perhitungan Struktur Beton Untuk Bangunan Gedung," Jakarta, 2013. 